UCRL-ID-128946

\title{
Results of MPBX Studies at the Single Heater Test
}

\author{
S.C. Blair
}

October 1997

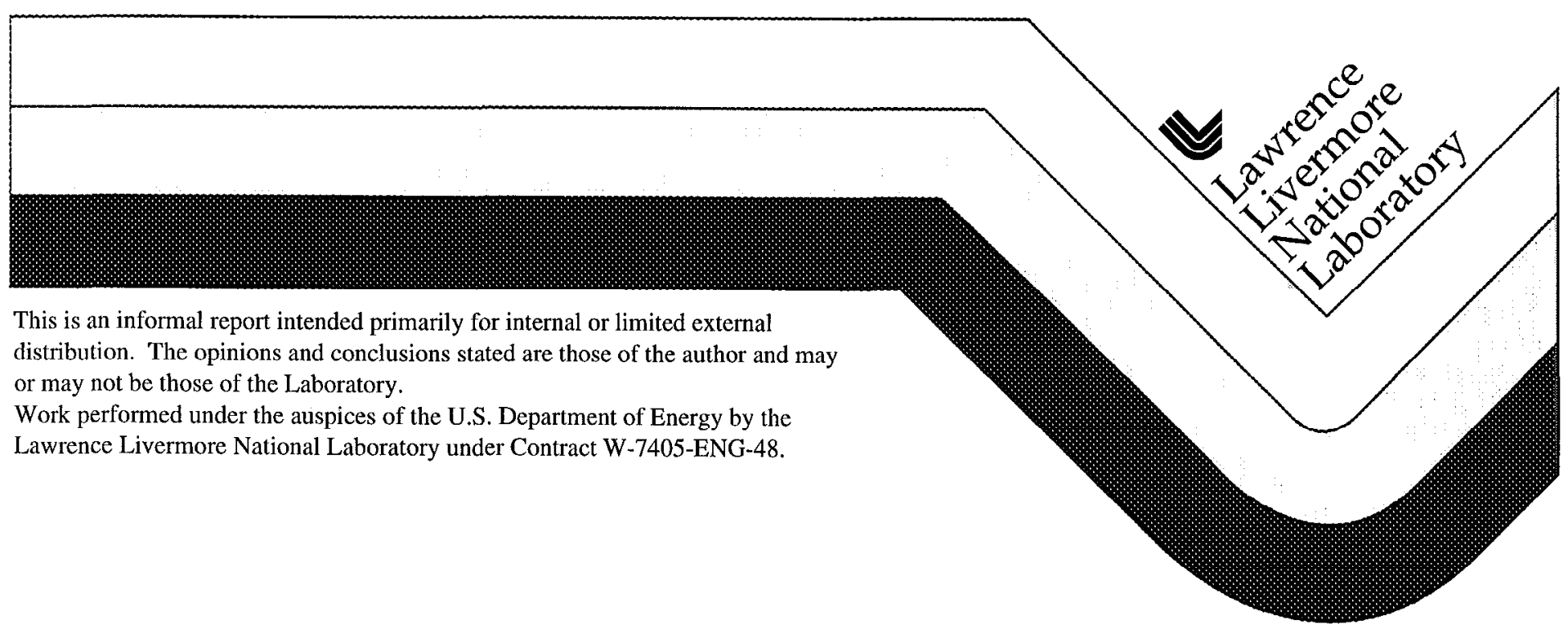




\section{DISCLAIMER}

This document was prepared as an account of work sponsored by an agency of the United States Government. Neither the United States Government nor the University of California nor any of their employees, makes any warranty, express or implied, or assumes any legal liability or responsibility for the accuracy, completeness, or usefulness of any information, apparatus, product, or process disclosed, or represents that its use would not infringe privately owned rights. Reference herein to any specific commercial product, process, or service by trade name, trademark, manufacturer, or otherwise, does not necessarily constitute or imply its endorsement, recommendation, or favoring by the United States Government or the University of California. The views and opinions of authors expressed herein do not necessarily state or reflect those of the United States Government or the University of California, and shall not be used for advertising or product endorsement purposes.

This report has been reproduced directly from the best available copy.

Available to DOE and DOE contractors from the

Office of Scientific and Technical Information

P.O Box 62, Oak Ridge, TN 37831

Prices available from (423) 576-8401

Available to the public from the

National Technical Information Service

U S Department of Commerce

5285 Port Royal Rd.

Springfield, VA 22161 


\title{
Results of MPBX Studies
}

\author{
at the
}

\section{Single Heater Test}

\author{
S. C. Blair \\ Prepared for \\ Yucca Mountain Site Characterization Project
}

Deliverable No. SP1090M4

WBS 1.2.3.14.2

Lawrence Livermore National Laboratory

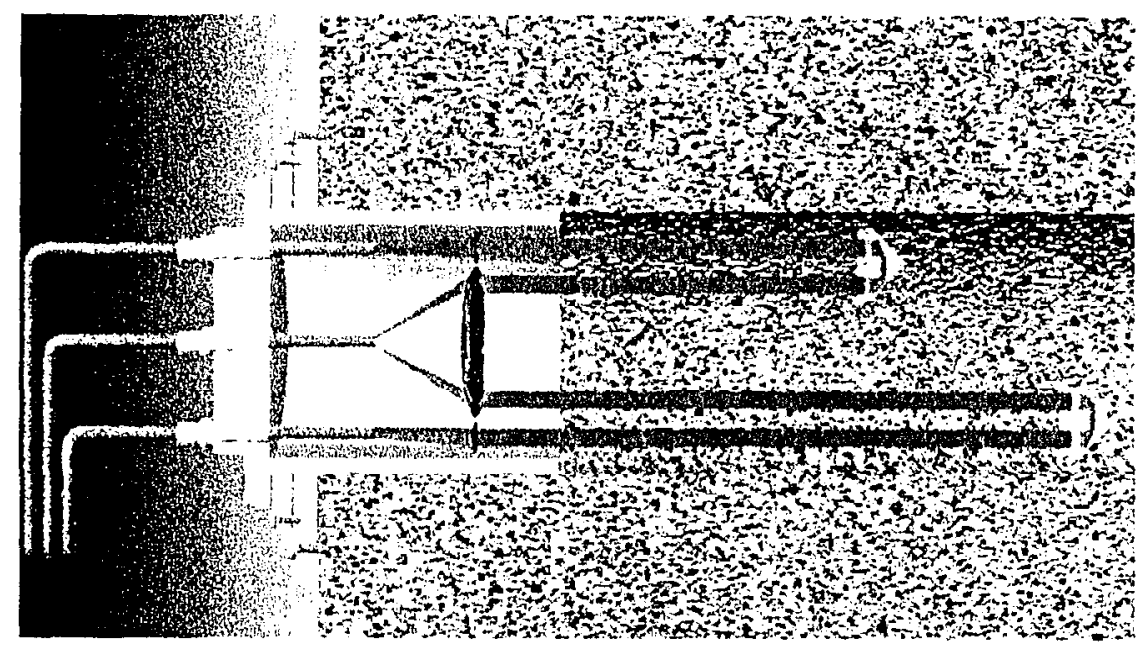




\begin{abstract}
We have developed an extensometer for measurement of distance and displacements in a geologic repository for high-level nuclear waste. This is an optical extensometer that measures distance using a modulated laser beam. In this design, reflecting targets are placed at desired measurement locations, and distance between each target and an optical head are measured repeatedly using the modulated laser beam. Moreover, all electronic and moving parts are located outside of the hostile or difficult environment as the optical head is connected to the laser, switching and signal analysis hardware using optical fibers. $\Lambda$ reference beam is utilized to provide direct correction of system behavior. The system also utilizes movable refleclive anchors that can be repositioned if desired. We have installed the system in the Single Heater Test being conducted in Alcove 5 of the Exploratory Studies Facility at Yucca Mountain, and report preliminary results.
\end{abstract}

\title{
INTRODUCTION AND MOTIVATION
}

Measurement of deformation in boreholes encountered in geotechnical or civil engineering applications is often accomplished using rod, wire or tape extensometers. These are commonly referred to as multi-point borehole extensometers (MPBX). In these units, anchors are placed at selected points, and long rods, wires or tapes, connected to the anchors extend to an extensometer head assembly located at the borehole collar, and the movement of the anchors is assumed to be the same as the movement of the rod ends. In these units displacement transducers are located in the extensometer head assembly. These extensometers exhibil a variety of measurement problems and may not be able to be recalibrated if located in a high temperature or otherwise inaccessible or hostile environment. In recent tests at elevated temperatures appropriate to a geologic repository for high-level radioactive waste, failure rates of $50 \%$ for the transducers have also been observed (Martino and Read, 1996), and while conventional displacement transducers, can be ruggedized for use in high temperature or otherwise hostile environments, the ruggedized versions are often quite expensive costing as much as several thousand dollars per transducer. In addition, conventional MPBX applications often require that the rods, wires or tapes be tensioned, so that the anchors are permanently affixed at the measurement point. Consequently, interpretation of the data requires that several assumptions be made. In particular, the tensioned rods, wires or tapes are assumed to have small thermal response and tension is assumed to remain uniform during the duration of the measurement. Another limitation of conventional designs is range. The transducer used must be selected based on the anticipated amount of movement and the precision required for the analysis. Finally, the rods used in these extensometers often experience corrosion when used in high temperature rock engineering environments

The development of inexpensive lasers and optical fiber technology offers the potential to eliminate many of the above problems. We have conducted a review of available technologies to assess their suitability for application to a geologic repository for high-level nuclear waste. Results of this review are presented in Table 1. 
Table 1. Summary of available technologies for underground deformation measurements. Technology

Pro

Con

\begin{tabular}{lll}
\hline MPBX - Mechanical & $\begin{array}{l}\text { Shelf } \\
\text { Good Precision }\end{array}$ & $\begin{array}{l}\text { \$\$\$ for High Temp., } \\
\text { Temp. correction is } \\
\text { Tedious, } \\
\text { Limited Range }\end{array}$ \\
MPBX-Acoustic & Shelf & $\begin{array}{l}\text { Unsuitable for high T } \\
\text { Optical-Theodolite }\end{array}$ \\
Interferometer & $\begin{array}{l}\text { Shelf, Flexible, Best for } \\
\text { Large Distances }\end{array}$ & $\begin{array}{l}\$ \$ \$, \\
\text { Manual Technique }\end{array}$ \\
& $\begin{array}{l}\text { High Precision } \\
\text { No Moving Parts }\end{array}$ & $\begin{array}{l}\$ \$ \$ \text {, Limited Range, } \\
\text { Uninterrupted Power } \\
\text { Needs Development }\end{array}$ \\
Phase Modulated Laser & $\begin{array}{l}\text { Flexible } \\
\text { Wide Range } \\
\text { No Moving Parts }\end{array}$ & Needs Development
\end{tabular}

Based on this review we have developed an optical extensometer for use in the high temperature environment expected in a geologic repository for high-level nuclear waste. Our instrument utilizes a phase modulated laser and optical fiber technology. Some of the advantages of this instrument are:

- Because optical technology is used, no moving parts are located in high temperature or otherwise inaccessible regions such as that expected in a high level nuclear waste repository.

- Because the signal is transmitted over optical cables, electrical noise and resistance are eliminated.

- Recalibration is simplified by incorporating a system correction into the design,

- All electronic and switching components are located outside the high temperature or otherwise hostile environment,

- Measurements can be made over a wide range of lengths, from a few $\mathrm{cm}$ to $60 \mathrm{~m}$,

- Anchors are attached to the rock at discrete isolated locations, eliminating tensioned rods, tapes and wires. 


\section{DESCRIPTION}

This is an optical extensometer that measures distance using an amplitude modulated laser beam. The principle of the laser ranging instrument is illustrated in Figure 1 .


- Wavelength and relative phase determine measurement accuracy

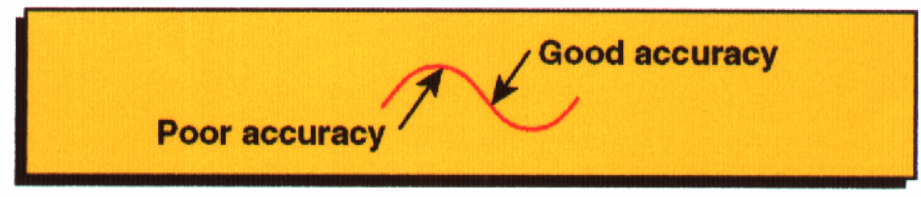

- Phase shift repeats after 1 wavelength

- Abosolute distance must be determined

- Two-frequency modulation

Figure 1. Illustration of how a modulated signal can be used to measure distance.

In this design, reflecting targets are placed at desired measurement locations, e.g. along the length of a borehole, and distance between each target and an optical head located at the collar of the borehole are measured repeatedly using the modulated laser beam. That is, the laser is aimed at a target, and a portion of the reflected beam is collected by a photodiode located in the instrument as shown in Figure 2. 


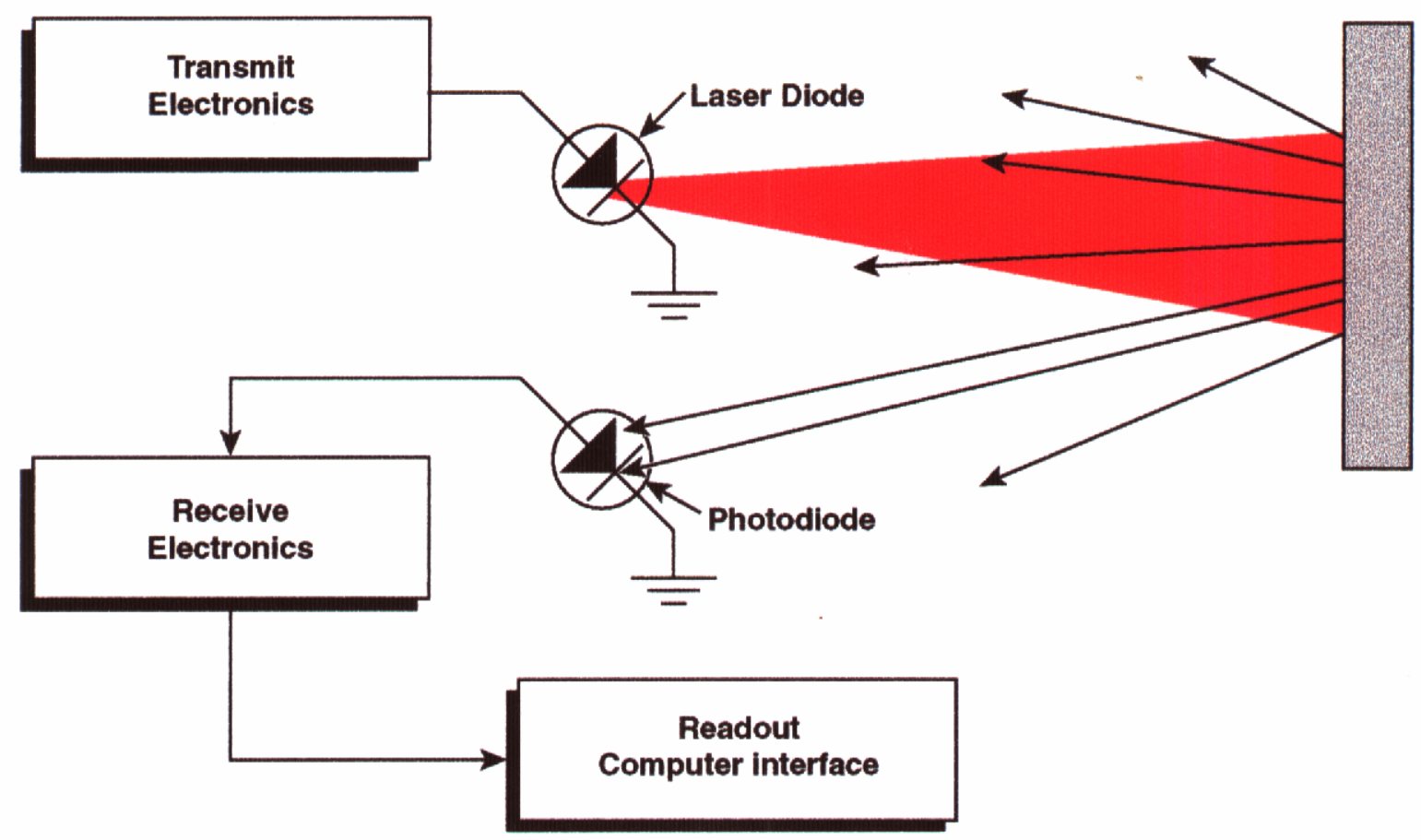

Figure 2. Schematic of distance measuring module.

The ROX optical borehole extensometer consists of the following components.

(1) an electro-optics module that contains a laser distance measuring device and optical switching apparatus. The distance measurement is done using the Refleks instrument from Phase Laser, Inc., Phoenix, Arizona (Woodbury, 1996). This instrument makes discrete distance measurements and utilizes frequency modulation of the laser amplitude. It has a measurement range of $2 \mathrm{~cm}$ to $60 \mathrm{~m}$, with theoretical precision of approximately 50 microns. The Phase Laser unit used in the distance measuring module has been modified to include fiberized laser diodes and photo diodes. The electro-optics module is controlled by a computer, and allows the user to determine laser intensity, switch between different optical fibers, record data on disk, and perform other data acquisition and control functions.

(2) An optical head and associated retro-reflectors. The laser beam is transmitted from the electro-optics module to the optical head using optical fibers. The optical head collimates the laser beam and transmits it to a retro-reflector(s) located at desired measurement points. The return beam is collected by a lens located in the optical head that focuses the beam onto an optical fiber, which transmits the beam back to the electro-optics module. The design of the optical head and associated downhole reflectors is shown in Figure 3.

We have implemented the system into a borehole extensometer shown in Figure 4 for measuring axial deformation of a borehole. Our prototype is a four channel system and the optical head is set up with four sets of collimating lenses located concentrically at 0,90 , 180 , and $270^{\circ}$ about the axis of the head. One of the beams is used as a reference, and the three others are used for measurements. Three borehole anchors containing retro-reflectors are placed at different depths in the borehole and each is oriented to one of the prescribed rotations. The instrument measures the distance to each retro-reflector and the reference in sequence, repeating the measurement at prescribed intervals, and averaging and recording as directed. 


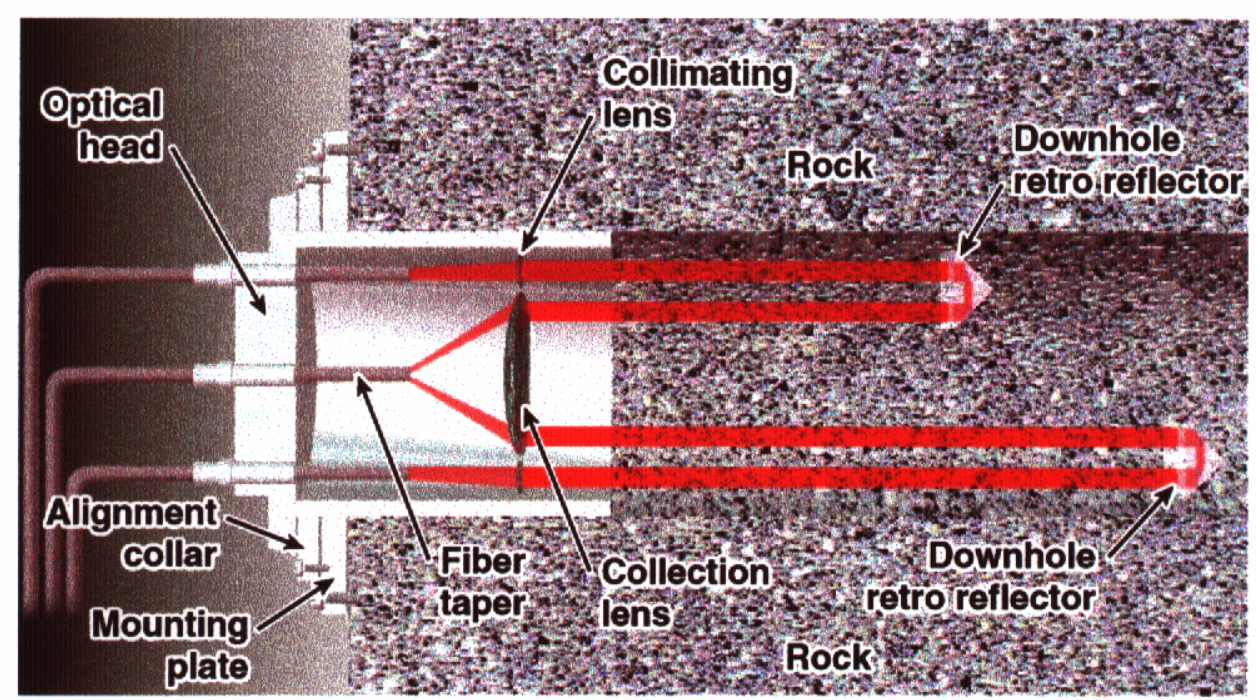

Figure 3. Schematic of optical head and downhole reflectiors used for ROX system 


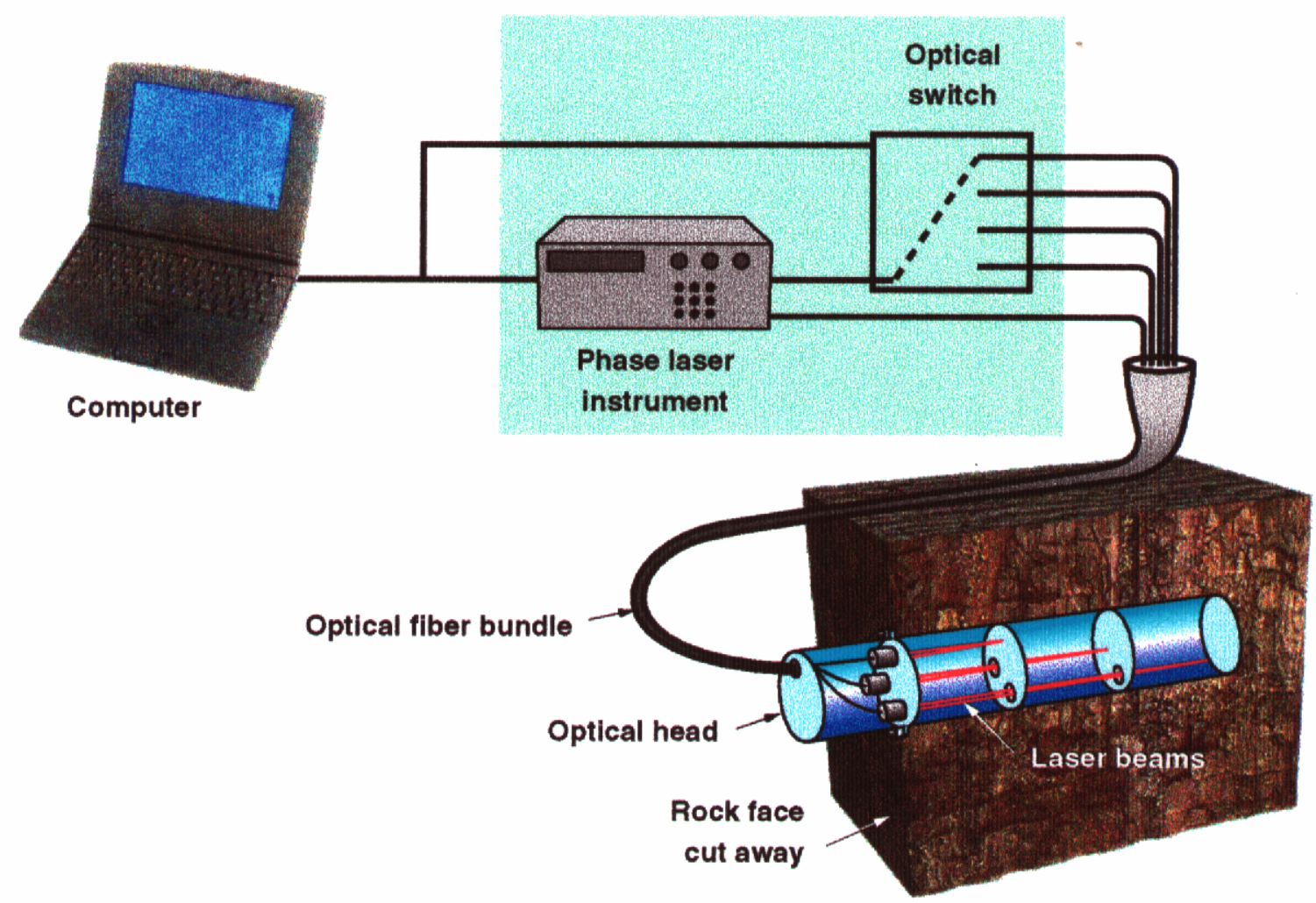

Figure 4. Schematic of ROX borehole extensometer system.

In addition, we have developed a system for emplacing, positioning, and retrieving retroreflectors (and other anchors) in wells and boreholes. The system provides a method for the rotational orientation of the anchors. This is accomplished by locating a mercury switch on the installation tool. Once the anchor is at the desired location in the hole, it is rotated until the switch indicates that it is properly oriented. Then a screw driven wedge is used to secure the anchor in place. The installation tool can also be used to retrieve the anchors. The installation tool and one reflective anchor are shown in Figure 5. 


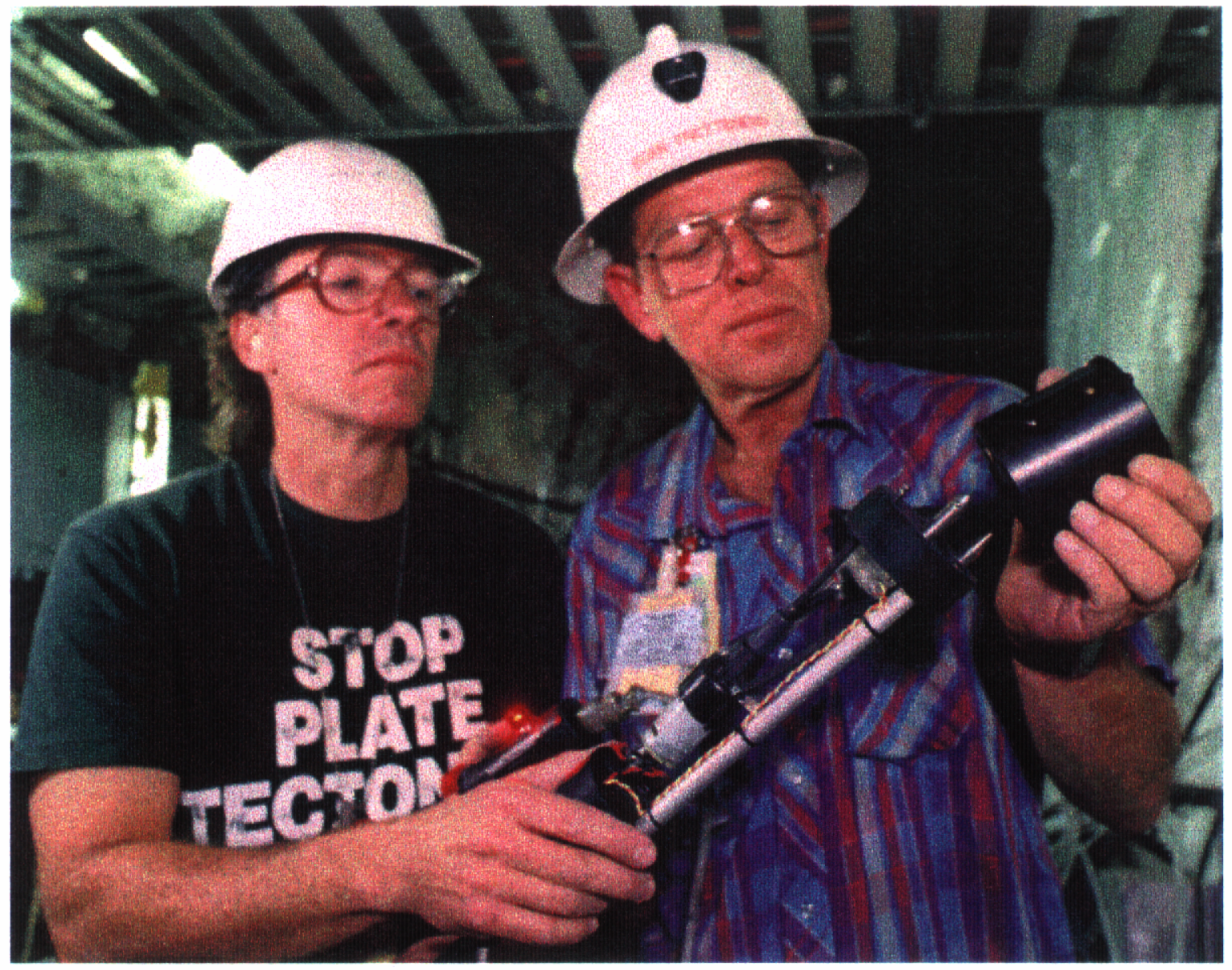

Figure 5. Borehole anchor and installation tool prior to installation in Single Heater Test. 


\section{RESULTS FOR SINGLE HEATER TEST}

We are currently using this system to monitor deformation in the Single Heater Test underway for the Yucca Mountain Site Characterization Project. This test is being conducted in the Exploratory Studies Facility at Yucca Mountain, Nye County, Nevada. The purpose of the single heater test is to monitor the thermal-mechanical-hydrologicchemical behavior of Topopah Spring Tuff. In this test a line heat source approximately 5 $\mathrm{m}$ long oriented in the horizontal plane. The ROX system was used to monitor position of reflective anchors in the placed in holes 6 and 7 of the Single Heater Test. These holes are in the horizontal plane and in directions parallel and perpendicular to the heater. Depths of the anchors from the borehole collar are given in Table 2 below.

Table 2. Locations of Anchors in Holes 6 and 7 of the Single Heater Test.

\begin{tabular}{lllll} 
Date & Hole & Anchor \# & Depth & Comment \\
\hline $8 / 20$ & 6 & 8 & $5.75 \mathrm{~m}\left(18^{\prime}-109 / 16^{\prime \prime}\right)$ & \\
& & 2 & $3.02 \mathrm{~m}\left(9^{\prime} 111 / 16^{\prime \prime}\right)$ & \\
& 1 & $1.52 \mathrm{~m}\left(5^{\prime} 0^{\prime \prime}\right)$ & Fracture at $8^{\prime}$ \\
$8 / 22$ & 7 & 2 & $3.92 \mathrm{~m}\left(12-109 / 16^{\prime \prime}\right)$ & \\
& & 1 & $2.09 \mathrm{~m}\left(6^{\prime}-109 / 16^{\prime \prime}\right)$ &
\end{tabular}

ROX measurements started in late August, 1996 and are continuing to the present. The system has operated nearly continuously over a period of several months in a location that was nearby to continuous mining operations including drill and blast, and mechanical excavation activities. Moreover, the optical switches and Phase Laser module were unaffected by the dust, shaking and constant electrical outages, etc. associated with the mining operations. Thus, we find that the system is rugged enough to hold up over extended periods in the underground environment.

\section{General Results}

The ROX system has operated successfully over an extended period from August 1996 to January 1997. Unfortunately during this period the quality of the data was not as good as expected. Data for the period November, 1996 to January, 1997 show extension over the measured interval, which is consistent with analytical predictions of the test, and with data observed using conventional MPBX systems in boreholes parallel with the ROX hole. While data from the ROX system are within an order of magnitude of the values observed by the conventional system, a higher precision result was expected, but was not obtained. This result is disappointing because as mentioned above, the Phase Laser instrument is capable of precision in the range of 50 microns. We are currently investigating the problem of precision and are working with Phase Laser, Inc. to improve the precision of the system.

During the installation we demonstrated the ability to make a measurement over a length of approximately $3 \mathrm{~m}$ with one anchor in the hole. However, when we placed multiple anchors in the hole we found that the shallower anchors blocked out some of the return beam from the deep anchors and while a detectable beam was returned from the deepest anchors, the signal level for them was below that required by the Phase Laser instrument. We have worked to increase the laser power and to improve the beam collimation in order 
to eliminate this problem, but to date had only limited success in monitoring multiple anchors simultaneously.

Both of the holes used for the ROX system were unlined, and we found that nearby drill and blast mining activities impacted the system. In particular, the blasting introduced a muddy mist into the boreholes which fogged the reflectors. Because the anchors were retrievable, we were able to pull them out, clean the reflectors and then reset the anchors in the holes.

\section{Results for Hole 6.}

This is a horizontal hole drilled parallel to the heater and approximately $1.5 \mathrm{~m}$ to the side and slightly above the heater. After approximately one month of heating a substantial amount of condensation occurred in the outer $2 \mathrm{~m}$ of the hole. This condensation fogged the lens on the optical head and a small air stream was introduced onto the head to keep the lens clear. Inspections showed that this moisture was entering the hole via a major fracture zone subparallel to the drift face and approximately $0.15 \mathrm{~m}$ from the drift wall. During the second month of heating the rock forming the outer $0.15 \mathrm{~m}$ of the drift wall displaced down and to the left approximately $6 \mathrm{~mm}$ in each direction. This precluded alignment of the laser head with the anchors, and measurements in this hole were terminated.

\section{Results for Hole 7.}

The ROX instrumentation for Hole 7 operated consistently from August, 1996 to January 1997. The data acquisition and control computer experienced a failure of the hard disk drive in January 1997. Consequently, the ROX system was not operational from January to June, 1997. Several upgrades were made to the system during this time including an upgrade to the laser ranging unit incorporated in the system, streamlining of the optical path, and revision of the software.

The system was brought back on-line in early June, 1997. However, during the period Feb. - May, 1997, significant amounts of moisture started moving into Hole \#7, probably associated with the heating. This moisture caused condensation on the optical head and a loss of signal from the unit. To overcome this, the system was used in a manual mode to obtain a measurement on 6/7/97. Reduced data are listed in Table 2 and plotted in Figure 6. These data indicate expansion followed by contraction and are not intuitive. However, there is a major fracture that intersects the hole between the two anchors. and this may indicate closing of the fracture due to thermal expansion. More work needs to be done to evaluate these data.

Table 3. Summary data for separation of anchors 2 and 8 in Hole 7 of the Single Heater Test.

\begin{tabular}{cc} 
Date & $\begin{array}{c}\text { Anchor Separation } \\
(\mathrm{mm})\end{array}$ \\
\hline $8 / 22 / 96$ & 1828.8 \\
$9 / 18 / 96$ & 1881.6 \\
$6 / 5 / 97$ & 1815.1
\end{tabular}

Figure 6. Deformation data from SHT, Hole 7. This shows expansion, followed by contraction, which is not intuitive behavior for rock in this location. Further analysis is required. 




\section{Results for current reporting period.}

The status of Hole \#6 remains unchanged from the previous deliverable, in that rock forming the outer few inches of the drift wall has moved so that the borehole collar is no longer coaxial with the remainder of the borehole. This precludes deformation measurements in this hole.

The status of Hole \#7. During this reporting period no data were recorded. This is due to problems experienced with maintaining alignment of the collection module. As discussed above, the design requires that the collection taper be positioned so that all reflected beams can be sampled in sequence. The alignment of this module has proved to be difficult to maintain when it is optimized for multiple light paths, and loss of alignment has caused a loss of signal. We have assessed the situation and are planning to conduct a series of manual measurements at intervals of a few weeks during the next reporting period. This type of measurement will collect information from one reflector at a time, and will preclude the need for the difficult alignment geometry encountered during the past reporting period. 


\section{SUMMARY}

We have developed an optical extensometer for use in the high temperature environment that is expected in a geologic repository for nuclear waste. This instrument is flexible and rugged and can be used in a variety of other geotechnical and civil engineering applications. The system has many advantages over conventional rod extensometers, as there are no moving parts in the borehole and a system correction is incorporated in the design. Some problems were encountered. However, the system is still under development and we hope to improve the system performance and data quality in future realizations of this instrument.

\section{REFERENCES}

I in, W et al. (1997). Thermal-mechanical-hydrological-chemical responses in the Single Heater Test at the ESF. submitted to New York Rocks, 36th US Rock Mechanics Symposium, June 29-July 2, 1997.

Martino, J. and Read, R. (1996). AECL's heated failure tests: An overview. Intemational Soc. for Rock Mechanics News Journal , 4:1, ISRM Secretariat, P-1799, Lisboa Codex, Portugal.

Woodbury, N., Brubacher, $M$ and Woodbury, J. The frequency-modulated laser tank gauge: designing a practical system. Sensors, 13:9, Sept., 1996. 


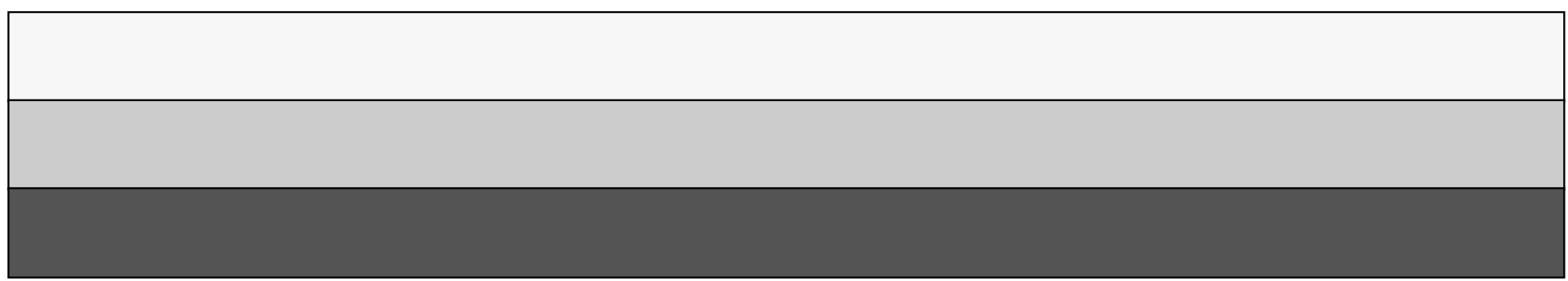

